\title{
Construção e validação preliminar de instrumento para a compreensão do ensino das lutas na educação física escolar
}

\author{
Marcos Paulo Vaz De Campos PEREIRA* (D), Íris Dantas da MOTA (D), Elias Barboza \\ LACERDA (D) \& Gelcemar Oliveira FARIAS (D) \\ Programa de Pós-Graduação em Ciências do Movimento Humano, Universidade do Estado de Santa \\ Catarina (Brazil)
}

Received: 17/11/2019; Accepted: 23/01/2020; Published: 27/01/2020.

\begin{abstract}
Resumo
O objetivo deste estudo foi construir e validar de forma preliminar um questionário de ensino das lutas e do jogo (QELJ), contribuindo para entender como está sendo realizado o ensino das lutas na educação física escolar. A elaboração das dimensões do instrumento baseou-se na literatura em lutas e jogo. 0 processo de validação de conteúdo foi realizado por cinco juízes experts na área. $\mathrm{O} \mathrm{V}$ de Aiken foi usado para quantificar a concordância entre especialistas. Além disso, foi realizado a testagem do instrumento com 17 professores de educação física em dois momentos, com intervalo de 14 dias entre cada momento. 0 software NVivo 9.2 foi usado para análise de conteúdo nas respostas dos participantes. Os resultados mostraram altas taxas de concordância positiva entre os avaliadores, todos acima de 0,80. 0 estudo piloto também apresentou bons resultados de confiabilidade na análise das respostas dos participantes nos dois momentos (97\% para questões fechadas, 82\% para questões abertas). Conclui-se que o QELJ provou ser um instrumento válido e útil para melhorar a compreensão do ensino das lutas na educação física escolar, embora outras avaliações psicométricas do instrumento devam ser realizadas no futuro.
\end{abstract}

ORIGINAL PAPER

Palavras-chave: Artes Marciais; esportes de combate; lutas; ensino; escola; educação física.

\footnotetext{
Construcción y validación preliminar de un instrumento para la compresión de la enseñanza de las luchas en educación física escolar

Resumen

El objetivo de este estudio fue construir y validar de forma preliminar un cuestionario sobre la enseñanza de las luchas y juegos (QELJ), y con ello facilitar la comprensión sobre cómo se enseñan las luchas en educación física escolar. Las dimensiones del instrumento fueron creadas a partir de literatura sobre luchas y juegos. El proceso de validación de contenido fue realizado por cinco jueces expertos. Se utilizó la V de Aiken para cuantificar la concordancia entre expertos. Además, se administró el QELJ a 17 profesores de educación física en dos momentos, con un intervalo de 14 días entre ellos. El software NVivo 9.2 se utilizó para realizar un análisis de contenido de las respuestas de los participantes. Los resultados mostraron altas tasas de acuerdo positivo entre evaluadores, por encima de 0,80 . El estudio piloto también registró buenos resultados de fiabilidad en el análisis de las respuestas de los participantes (97\% para preguntas cerradas, $82 \%$ para preguntas abiertas). Se puede concluir que el QELJ demostró ser una herramienta válida y útil para mejorar la comprensión de la enseñanza de la lucha en educación física escolar, aunque en el futuro deban realizarse evaluaciones psicométricas adicionales del instrumento.

Palabras clave: Artes marciales; deportes de combate; luchas, enseñanza; escuela; educación física.
}

\section{Construction and preliminary validation of an instrument for understanding fighting teaching in school physical education \\ Abstract}

The purpose of this study was to construct and conduct a preliminary validation of the questionnaire on fighting and games teaching (QELJ), thus contributing to understand how fighting in school physical education is being taught. The dimensions of the instrument were created on the basis of the literature in fighting and games. The content validation process was performed by five expert judges in the field. Aiken's V was used to quantify concordance between experts. In addition, the QELJ was tested with 17 physical education teacher in two moments, with an interval of 14 days between them. NVivo 9.2 software was used for content analyses on participants' answers. The results showed high positive agreement rates among the evaluators, all above 0.80 . The pilot study also presented good reliability results in the analysis of participants' responses in the two moments ( $97 \%$ for closed questions, $82 \%$ for open questions). It can be concluded that the QELJ proved to be a valid and useful tool to improve the understanding of the teaching of fighting in school physical education, although other psychometric evaluations of the instrument should be carried out in the future.

Keywords: Martial arts; combat sports; fighting; teaching; school; physical education.

\footnotetext{
${ }^{*}$ E-mail: marcosp.pereira46@gmail.com
} 


\section{Introdução}

As lutas enquanto uma manifestação da cultura corporal, se apresentam como um dos macro conteúdos da educação física escolar, sendo contempladas em documentos curriculares norteadores de domínio público (Correia, 2015; Antunes, 2016; Kusnierz, Cynarski, \& Gorner, 2017). Além disso, autores corroboram com propostas metodológicas para o ensino das lutas no âmbito escolar, objetivando sua utilização de maneira organizada e sistematizada, permitindo no desenvolvimento da prática pedagógica do professor o ensino deste conteúdo, bem como o aprendizado dos alunos nos vários níveis da educação básica (Olivier, 2000; Cirino, Pereira, \& Scaglia, 2013; Rufino, 2016; Pereira, Cirino, Correa, \& Farias 2017).

Como principal estratégia de ensino para as lutas no âmbito escolar, o jogo adentra neste contexto. Ademais, autores se respaldam em jogos de oposição e jogos que contenham características das lutas para embasar em suas propostas e com isso subsidiar os professores em sua prática pedagógica diária, tornando o conteúdo possível de ser tematizado em sua plenitude, diversificando com diversas manifestações de lutas e em dimensões procedimentais, conceituais e atitudinais, ambas atreladas ao jogo (Theebom \& De Knop, 1999; Olivier, 2000; Avelar \& Figueiredo, 2009; Pereira, Cirino, Correa, \& Farias 2017).

Nesse sentido, o jogo, atividade voluntária com caráter lúdico e pedagógico, contendo regras, tempo, espaço, jogadores e suspensão da realidade (Caillois, 1990) se apresenta como um conteúdo, mas também uma estratégia para ensinar os conteúdos da educação física, no caso as lutas. Para tanto, requer do professor se debruçar em estudar o jogo em consonância com as lutas, e com isso organizar e sistematizar o conteúdo por meio de aulas diversificadas, pautadas no ato de jogar, criando jogos que contemplem as características das lutas (tocar, agarrar, projetar, cair, rolar, esquivar, dentre outras) (Pereira, Cirino, Correa, \& Farias 2017).

Por outro lado, apesar de indícios da inserção do conteúdo de lutas na educação física escolar e estratégias como o jogo para ensinar as lutas, paradigmas permeiam para a sua restrição, a saber: nas lutas ainda são atribuídas à menções de violência, receio do professor em utilizar o conteúdo por nunca ter sido um praticante de algum tipo de lutas, ou até mesmo não ter contato em alguma disciplina de lutas na graduação (Nascimento \& Almeida, 2007; Rufino \& Darido, 2012; Galatti, Cirino, \& Scaglia, 2015). Estas restrições por parte dos professores e estendendo para a sociedade implica no afastamento do conteúdo do âmbito escolar o que limita o ensino de um dos conteúdos da educação física.

Ademais, quando o conteúdo é tematizado pelos professores, outros paradigmas emergem, a saber: ensino por repetições exaustivas de técnicas, priorizando apenas o movimento (gesto motor), ensino das lutas na escola muitas vezes similar ao da academia, limitação de apenas uma modalidade de luta, no qual geralmente é a modalidade que o professor foi praticante (Cirino, Pereira, \& Scaglia, 2013; Galatti, Cirino, \& Scaglia, 2015; Jennings, 2017). Estas maneiras de ensino, em que não consideram a diversidade do conteúdo corroboram para um ensino descontextualizado e limitado das lutas.

Mediante ao contexto apresentado, gera a necessidade em investigar como o ensino das lutas se estabelece nas aulas de educação física escolar, compreendendo como o conteúdo é tematizado pelos professores, assim como as estratégias de ensino utilizadas. Além de estender para a compreensão do jogo, como uma estratégia de ensino ao alcance do professor. Nesse sentido instrumentos como questionários, entrevistas e diários de campo são fundamentais para investigar este cenário, e com isso, propor alternativas e expor práticas pedagógicas eficientes para o ensino das lutas no cenário escolar.

Para tanto na literatura, instrumentos de pesquisa para investigar o ensino das lutas e o jogo como estratégia de ensino no cenário escolar são escassos, ainda mais se tratando de questionários que são de suma importância para se obter um panorama de informações, abranger grandes populações a serem investigadas e coletar os dados em tempo reduzido (Gerhardt \& Silveira, 2009; Negrine, 2010). Nesse sentido, o objetivo deste estudo foi construir e validar de maneira preliminar o instrumento do tipo questionário de ensino das lutas e do jogo (QELJ) para compreender como está sendo realizado o ensino das lutas na educação física escolar. 


\section{Métodos}

\subsection{Construção do instrumento}

O questionário é um instrumento de sondagem, cuja importância se justifica por coletar grande número de informações em um tempo reduzido, sendo possível identificar o problema a ser estudado (Gerhardt \& Silveira, 2009; Negrine, 2010). 0 questionário empregado foi estruturado a partir de três partes: a primeira relacionada aos dados de identificação dos professores, a segunda contextualizou os conteúdos desenvolvidos na disciplina de educação física e a terceira foi reservada às propostas e as estratégias para o ensino das lutas, além dos fatores que determinam o seu ensino.

O processo de construção do questionário foi obtido por meio de uma matriz analítica (Hill \& Hill, 2000) (Tabela 1). A matriz analítica foi elaborada considerando as dimensões do instrumento: dados de identificação, conteúdos desenvolvidos e propostas e estratégias pedagógicas. A dimensão dados de identificação apresenta os seguintes indicadores: nome, sexo, idade, formação acadêmica, tempo de docência, escola que atua e tempo de atuação na escola investigada. Estes indicadores não apresentam base teórica. Se tratando da dimensão conteúdos desenvolvidos, seus indicadores foram: variedade de conteúdos, conhecimento sobre os conteúdos, jogo como conteúdo e conteúdo de lutas. Nesta dimensão, as questões foram respaldadas por uma base teórica (Freire \& Scaglia, 2003; Breda, Scaglia, Paes, \& Galatti, 2010; Santa Catarina, 2014; Galatti, Cirino, \& Scaglia, 2015; Brasil, 2017) para referenciar cada indicador. A terceira dimensão, nomeada de propostas e estratégias pedagógicas, seus indicadores foram: métodos utilizados, jogo como estratégia de ensino, benefícios do conteúdo de lutas e sistematização do conteúdo lutas. Mediante a literatura, as questões foram respaldadas por uma base teórica (Olivier, 2000; Cirino, Pereira, \& Scaglia, 2013; Pereira, Farias, Cirino, Scaglia, 2016) para subsidiar cada indicador.

Tabela 1. Matriz analítica do instrumento.

\begin{tabular}{|c|c|c|}
\hline Dimensão & Indicadores & Base teórica \\
\hline Dados de identificação & $\begin{array}{l}\text { Nome } \\
\text { Sexo } \\
\text { Idade } \\
\text { Formação acadêmica } \\
\text { Tempo de docência } \\
\text { Escola que atua } \\
\text { Tempo de atuação na escola investigada }\end{array}$ & Não se aplica \\
\hline $\begin{array}{l}\text { Conteúdos } \\
\text { desenvolvidos }\end{array}$ & $\begin{array}{l}\text { Variedade de conteúdos } \\
\text { Conhecimento sobre os conteúdos } \\
\text { Jogo como conteúdo } \\
\text { Conteúdo de lutas }\end{array}$ & $\begin{array}{l}\text { Freire \& Scaglia (2003); Breda, } \\
\text { Scaglia, Paes, \& Galatti (2010); Galatti, } \\
\text { Cirino, \& Scaglia (2014); Santa } \\
\text { Catarina (2014); Brasil (2017). }\end{array}$ \\
\hline $\begin{array}{l}\text { Propostas e estratégias } \\
\text { pedagógicas }\end{array}$ & $\begin{array}{l}\text { Métodos utilizados } \\
\text { Jogo como estratégia de ensino } \\
\text { Benefícios do conteúdo de lutas } \\
\text { Sistematização do conteúdo lutas }\end{array}$ & $\begin{array}{l}\text { Olivier (2000); Cirino, Pereira, \& } \\
\text { Scaglia (2013); Pereira, Cirino, Correa, } \\
\text { \& Farias (2017) }\end{array}$ \\
\hline
\end{tabular}

\subsection{Processo de validação de conteúdo do instrumento}

Após esse processo de construção da matriz analítica e da elaboração da estrutura do questionário, deu-se início ao processo de validação. Por sua vez, a validação do instrumento seguiu as orientações propostas por Cassepp-Borges, Balbinotti e Teodoro (2010), que visam determinar o nível de adequação ao estudo por meio da clareza de linguagem (termos e a linguagem utilizada para determinar cada questão), da pertinência prática (se a questão possui importância para que o instrumento propõe avaliar) e da relevância teórica (se refere a associação entre a questão e a teoria proposta).

Para que o instrumento fosse avaliado em cada um desses níveis, foi utilizado o protocolo de Pasquali (1999), o qual consiste na escolha de no mínimo cinco juízes para a avaliação de conteúdo do instrumento. Ademais, foram escolhidos cinco juízes com conhecimento e publicações na área das lutas para avaliar e atribuir conceitos a cada uma das questões, que o compõe. A escolha de 
cada um dos juízes se estabeleceu por meio de alguns critérios, quais sejam: formação acadêmica equivalente em nível de mestrado ou doutorado; ser um pesquisador sobre a temática lutas no ambiente escolar; ter sido professor da rede básica de ensino; atuar no ensino superior; e ministrar alguma disciplina sobre a temática em instituições de ensino superior. Contudo, foram escolhidos os juízes que atendiam no mínimo três dos critérios pré-estabelecidos, com o intuito de constituir uma avaliação rigorosa e apresentar novos olhares ao instrumento.

Com os cinco juízes selecionados e o aceite em participar do processo de validação, o instrumento foi enviado via e-mail, com as orientações para validação. Na sequência, cada juiz atribuiu um valor numa escala de um a cinco (1 pouquíssima, 2 pouca, 3 média, 4 muita, 5 muitíssima), para cada um dos três níveis (clareza da linguagem, pertinência prática e relevância teórica) em cada uma das questões.

Após o retorno do instrumento pelos juízes, iniciou-se o processo de confiabilidade de cada questão por meio das notas obtidas. Para realizar este cálculo, obedeceu-se aos seguintes critérios: cálculo da média das notas atribuídas de cada uma das questões, divididas por meio dos três níveis; e cálculo do coeficiente de confiabilidade das questões denominado V de Aiken em cada um dos níveis, que permite obter os intervalos de confiança entre os avaliadores nas questões. 0 coeficiente $\mathrm{V}$ de Aiken é uma técnica utilizada para quantificar a validade e/ou a relevância dos níveis em relação às notas atribuídas pelo número de juízes (Aiken, 1985). Esse coeficiente apresenta variações de magnitude de 0,00 a 1,00, quanto maior a magnitude, maior o nível de concordância e confiabilidade do instrumento. A fórmula para o cálculo da $V$ de Aiken é $V=(\bar{x}-l) / k$. A equação é apresentada pelo $\bar{x}$ sendo a média das notas dos juízes, l é a nota mais baixa e $\mathrm{k}$ é a faixa de valores possíveis, a saber: $\mathrm{l}=1 \mathrm{e} \mathrm{k}=5$, então $\mathrm{k}=5-1=4$. 0 cálculo deste coeficiente foi por meio do software de domínio público Visual Basic 6 (Merino \& Lívia, 2009), o qual permite obter a média das avaliações, o valor do V de Aiken. 0 ponto de corte estabelecido foi 0,80 , sendo que caso alguma questão apresentasse valor abaixo do estabelecido, a mesma seria reformulada ou suprimida seguindo as observações dos juízes, e após enviado o instrumento novamente para a reavaliação dos juízes.

\subsection{Testagem do instrumento}

Após a validação do questionário deu-se início o estudo piloto, que se faz necessário, no intuito de verificar se os itens do instrumento estavam adequados, como também, um meio para detectar possíveis erros (Cassepp-Borges, Balbinotti, \& Teodoro, 2010). Participaram do estudo piloto 17 professores de educação física da educação básica de escolas da Grande Florianópolis, Santa Catarina. O momento visou a análise do instrumento, e com isso, possíveis ajustes que poderiam ser realizados antes da coleta oficial dos do projeto, para o qual se destinada a construção do questionário.

É importante ressaltar que este estudo é um recorte do projeto de pesquisa intitulado "As lutas no ensino da educação física escolar: uma proposta metodológica por meio de redes complexas dos jogos". Como também, o projeto foi aprovado pelo Comitê de Ética em Pesquisa com Seres Humanos da Universidade do Estado de Santa Catarina (parecer n. 2.380.744/2017) respeitando os aspectos éticos para a realização do estudo piloto, e com isso a testagem do instrumento.

O estudo piloto foi realizado em outubro de 2017 em uma formação pedagógica dos participantes na Universidade do Estado de Santa Catarina. O pesquisador em um primeiro momento fez a arguição sobre o estudo, e após, foi entregue o instrumento aos participantes para ser respondido juntamente com o Termo de Consentimento Livre e Esclarecido, documento que consiste nos procedimentos éticos e as orientações sobre o estudo, o qual foi assinado pelos participantes, sendo uma via ficava em posse do participante e a outra com o pesquisador.

Mediante a recolha dos questionários devidamente respondidos em aproximadamente cinquenta minutos pelos professores, foram analisadas as respostas, como também agendado uma nova coleta em um intervalo de tempo de 14 dias, esta coleta também foi realizada em uma formação pedagógica com os mesmos procedimentos da primeira etapa e na mesma localidade. É importante ressaltar que o intervalo estabelecido foi respaldado em Pasquali (1999) que menciona 
a importância da similaridade das respostas obtidas na primeira e segunda coleta, com isso as questões do instrumento apresentam uma consistência no que se propõe avaliar.

Para a análise das respostas, foi utilizado o processo de análise de conteúdo proposta por Bardin (1977), sendo realizada por meio de três etapas, a saber: pré-análise, que consistiu na leitura das respostas dos professores na primeira e segunda coleta; codificação, que consistiu na elaboração de unidades de registro; e a categorização mediante as respostas obtidas. É importante mencionar, que para cada questão foi construída uma categoria para a comparação da similaridade das respostas, além disso, foi utilizado o software NVivo 9.2 em cada uma das fases para melhor organizar todo o material.

\section{Resultados}

Com a validação de conteúdo realizada pelos juízes, e os coeficientes devidamente calculados, algumas questões ficaram abaixo do ponto de corte $(0,80)$. Para tanto, foram realizadas as reformulações, que se estabeleceram pelos novos olhares e pelas sugestões acatadas dos juízes. É importante ressaltar que o questionário, inicialmente, era composto por 34 questões, mediante a este momento o instrumento foi reduzido para 29 questões. Sendo eliminadas três questões as quais os juízes julgaram não atender os objetivos da dimensão conteúdos desenvolvidos, e duas questões foram acopladas no indicador métodos utilizados.

Seguidamente, com o instrumento devidamente alterado, foi realizado um novo processo de validação pelos juízes seguindo as mesmas diretrizes da validação de conteúdo. Após esta segunda rodada de avaliação, todas as 29 questões ficaram acima do ponto de corte, totalizando como média do questionário a confiabilidade de 0,91 (Tabela 2).

Tabela 2. Validação por juízes experts.

\begin{tabular}{|c|c|c|c|c|c|c|c|c|c|c|c|c|c|c|c|c|c|c|c|c|c|}
\hline \multirow[b]{3}{*}{ Items } & \multicolumn{7}{|c|}{ Clareza de linguagem } & \multicolumn{7}{|c|}{ Pertinência prática } & \multicolumn{7}{|c|}{ Relevância teórica } \\
\hline & \multicolumn{5}{|c|}{ Juízes } & \multirow[b]{2}{*}{$M$} & \multirow[b]{2}{*}{$V_{\text {Aiken }}$} & \multicolumn{5}{|c|}{ Juízes } & \multirow[b]{2}{*}{$M$} & \multirow[b]{2}{*}{$V_{\text {Aiken }}$} & \multicolumn{5}{|c|}{ Juízes } & \multirow[b]{2}{*}{$M$} & \multirow[b]{2}{*}{$V_{\text {Aiken }}$} \\
\hline & 1 & 2 & 3 & 4 & 5 & & & 1 & 2 & 3 & 4 & 5 & & & 1 & 2 & 3 & 4 & 5 & & \\
\hline 1 & 4 & 5 & 5 & 4 & 4 & 4,4 & 0,85 & 5 & 5 & 5 & 5 & 5 & 5,0 & 1,0 & 5 & 4 & 5 & 5 & 4 & 4,6 & 0,90 \\
\hline 2 & 4 & 5 & 5 & 4 & 4 & 4,4 & 0,85 & 5 & 5 & 5 & 5 & 5 & 5,0 & 1,0 & 5 & 4 & 5 & 5 & 4 & 4,6 & 0,90 \\
\hline 3 & 4 & 5 & 5 & 4 & 4 & 4,4 & 0,85 & 5 & 5 & 5 & 5 & 5 & 5,0 & 1,0 & 5 & 4 & 5 & 5 & 4 & 4,6 & 0,90 \\
\hline 4 & 4 & 5 & 5 & 4 & 4 & 4,4 & 0,85 & 5 & 5 & 5 & 5 & 5 & 5,0 & 1,0 & 5 & 4 & 5 & 5 & 4 & 4,6 & 0,90 \\
\hline 5 & 4 & 5 & 5 & 4 & 4 & 4,4 & 0,85 & 5 & 5 & 5 & 5 & 5 & 5,0 & 1,0 & 5 & 4 & 5 & 5 & 4 & 4,6 & 0,90 \\
\hline 6 & 4 & 5 & 5 & 4 & 4 & 4,4 & 0,85 & 5 & 5 & 5 & 5 & 5 & 5,0 & 1,0 & 5 & 4 & 5 & 5 & 4 & 4,6 & 0,90 \\
\hline 7 & 4 & 5 & 5 & 4 & 4 & 4,4 & 0,85 & 5 & 5 & 5 & 5 & 5 & 5,0 & 1,0 & $J$ & 4 & 5 & 5 & 4 & 4,6 & 0,90 \\
\hline 8 & 5 & 5 & 5 & 5 & 4 & 4,8 & 0,95 & 5 & 5 & 5 & 5 & 4 & 4,8 & 0,95 & 5 & 5 & 5 & 5 & 3 & 4,6 & 0,90 \\
\hline 9 & 5 & 5 & 5 & 5 & 4 & 4,8 & 0,95 & 3 & 5 & 5 & 5 & 3 & 4,2 & 0,80 & 3 & 5 & 5 & 5 & 3 & 4,2 & 0,80 \\
\hline 10 & 5 & 5 & 5 & 5 & 4 & $4 ; 8$ & 0,95 & 5 & 5 & 5 & 5 & 3 & 4,6 & 0,90 & 5 & 5 & 5 & 4 & 3 & 4,4 & 0,85 \\
\hline 11 & 5 & 5 & 5 & 5 & 1 & 4,2 & 0,80 & 5 & 5 & 5 & 5 & 1 & 4,2 & 0,80 & 5 & 5 & 5 & 5 & 1 & 4.2 & 0,80 \\
\hline 12 & 5 & 5 & 5 & 5 & 4 & 4,8 & 0,95 & 5 & 5 & 5 & 5 & 4 & 4,8 & 0,95 & 5 & 5 & 5 & 5 & 4 & 4,8 & 0,95 \\
\hline 13 & 5 & 5 & 5 & 5 & 4 & 4,8 & 0,95 & 5 & 5 & 5 & 5 & 4 & 4,8 & 0,95 & 5 & 5 & 5 & 5 & 3 & 4,6 & 0,90 \\
\hline 14 & 5 & 5 & 5 & 5 & 4 & 4,8 & 0,95 & 5 & 5 & 5 & 5 & 4 & 4,8 & 0,95 & 5 & 5 & 5 & 5 & 4 & 4,8 & 0,95 \\
\hline 15 & 5 & 5 & 5 & 5 & 4 & 4,8 & 0,95 & 5 & 5 & 5 & 5 & 3 & 4,6 & 0,90 & 5 & 5 & 5 & 5 & 3 & 4,6 & 0,90 \\
\hline 16 & 5 & 5 & 5 & 4 & 3 & 4,4 & 0,85 & 5 & 5 & 5 & 5 & 4 & 4,8 & 0,85 & 5 & 5 & 5 & 5 & 4 & 4,8 & 0,95 \\
\hline 17 & 5 & 5 & 5 & 5 & 4 & 4,8 & 0,95 & 5 & 5 & 5 & 5 & 4 & 4,8 & 0,95 & 5 & 5 & 5 & 5 & 4 & 4,8 & 0,95 \\
\hline 18 & 5 & 5 & 5 & 5 & 4 & 4,8 & 0,95 & 5 & 5 & 5 & 4 & 4 & 4,6 & 0,90 & 5 & 5 & 5 & 5 & 4 & 4,8 & 0,95 \\
\hline 19 & 5 & 5 & 5 & 5 & 4 & 4,8 & 0,95 & 5 & 5 & 5 & 5 & 4 & 4,8 & 0,95 & 5 & 5 & 5 & 5 & 4 & 4,8 & 0,95 \\
\hline 20 & 5 & 5 & 4 & 5 & 2 & 4,2 & 0,80 & 5 & 5 & 5 & 5 & 2 & 4,4 & 0,85 & 5 & 5 & 5 & 5 & 3 & 4,6 & 0,90 \\
\hline 21 & 5 & 5 & 5 & 5 & 4 & 4,8 & 0,95 & 5 & 5 & 5 & 5 & 4 & 4,8 & 0,95 & 5 & 5 & 5 & 5 & 4 & 4,8 & 0,95 \\
\hline 22 & 3 & 5 & 5 & 5 & 3 & 4,2 & 0,80 & 5 & 5 & 5 & 5 & 3 & 4,6 & 0,90 & 5 & 5 & 5 & 5 & 4 & 4,8 & 0,95 \\
\hline 23 & 5 & 5 & 5 & 5 & 3 & 4,6 & 0,90 & 5 & 5 & 5 & 5 & 3 & 4,6 & 0,90 & 5 & 5 & 5 & 5 & 2 & 4,4 & 0,85 \\
\hline 24 & 5 & 5 & 5 & 5 & 4 & 4,8 & 0,95 & 5 & 5 & 5 & 5 & 4 & 4,8 & 0,95 & 5 & 5 & 5 & 5 & 4 & 4,8 & 0,95 \\
\hline 25 & 4 & 5 & 5 & 5 & 4 & 4,6 & 0,90 & 5 & 5 & 5 & 5 & 4 & 4,8 & 0,95 & 5 & 5 & 5 & 5 & 4 & 4,8 & 0,95 \\
\hline 26 & 5 & 5 & 5 & 5 & 4 & 4,8 & 0,95 & 5 & 5 & 5 & 5 & 4 & 4,8 & 0,95 & 5 & 5 & 5 & 4 & 4 & 4,6 & 0,90 \\
\hline 27 & 5 & 5 & 5 & 4 & 4 & 4,6 & 0,90 & 5 & 5 & 5 & 5 & 4 & 4,8 & 0,95 & 5 & 5 & 5 & 5 & 4 & 4,8 & 0,95 \\
\hline 28 & 5 & 5 & 3 & 4 & 4 & 4,2 & 0,80 & 5 & 5 & 5 & 5 & 4 & 4,8 & 0,95 & 5 & 5 & 5 & 5 & 4 & 4,8 & 0,95 \\
\hline 29 & 5 & 5 & 5 & 4 & 4 & 4,6 & 0,90 & 5 & 5 & 5 & 5 & 4 & 4,8 & 0,95 & 5 & 5 & 5 & 5 & 4 & 4,8 & 0,95 \\
\hline
\end{tabular}


Com relação a concordância entre os juízes, pode-se observar que as médias das notas atribuídas foram satisfatórias, como também o coeficiente de confiabilidade (V de Aiken) em cada questão. Nesse sentido, apenas um juiz, o número 5 que apresentou maiores divergências entre os demais. Porém, não acarretou implicações ao instrumento, devido aos outros quatro juízes apresentarem similaridade em suas avaliações.

Se tratando da testagem do instrumento, no estudo piloto, as respostas obtidas no primeiro momento em comparação com as respostas do segundo momento foram similares, e precisaram apenas de refinamentos pontuais em algumas questões (ajustes em palavras) que não foram perceptíveis anteriormente. As questões fechadas atingiram similaridade de 97\%, e as questões abertas, por mais que fosse ampla e exigissem um grande esforço cognitivo, atingiram similaridade de $82 \%$ mediante a análise de conteúdo respaldada pelo software NVivo 9.2. Com isso, o instrumento mesmo com questões abertas, consegue atingir o objetivo proposto, apresentando consistência em todas as 29 questões.

\section{Discussão}

As lutas enquanto um conteúdo da educação física ainda carece de investigações, tanto por parte do ensino dos professores, quanto pela aprendizagem dos alunos (Rufino \& Darido, 2012; Correia, 2015). Neste sentido, percebe-se uma crescente preocupação dos pesquisadores com os processos de ensino e de aprendizagem das lutas nas aulas de educação física, como por exemplo o estudo de caso de Avelar-Rosa e López-Ros (2019) que investigou uma sequência didática de ensino de jogos nas lutas em uma escola primária de Portugal, como também o estudo de AljadeffAbergel (2013) o qual propõe também uma sequência pedagógica de jogos para o ensino do Karatê na escola. Tais estudos, apesar de importantes para que professores possam explorar o jogo, como também sistematizações de ensino para as lutas, ainda requerem instrumentos de investigação para averiguar possíveis angústias, paradigmas e propostas de ensino que irão contribuir para o avanço científico e pedagógico das lutas no contexto escolar.

Em consonância, este instrumento apresenta como objetivo compreender como está sendo realizado o ensino das lutas na educação física escolar. Mediante este objetivo, contribuir para o avanço de estudos acerca do ensino das lutas no âmbito escolar, como também contribuir com a prática pedagógica de professores. Nesse sentido, as dimensões do questionário e cada questão foram construídas considerando o ensino dos conteúdos, o conhecimento do professor acerca do jogo enquanto uma estratégia de ensino e as lutas enquanto o conteúdo (Freire \& Scaglia, 2003; Pereira, Cirino, Correa, \& Farias 2017), tendo em vista as lutas o foco do instrumento. Pode-se mencionar que o instrumento contribuiu com estudos voltados a lutas na educação física escolar, e com a sua diversidade de questões, também pode favorecer com o avanço científico em torno do ensino do professor, juntamente com os paradigmas em torno das lutas que distanciam este conteúdo no cenário escolar.

Com relação a validação de conteúdo, Hermida e Araújo (2006) discorrem a importância de modificações necessárias mediante as notas e sugestões dos juízes experts, fato que ocorreu no processo de validação, e que após a segunda rodada as notas dos juízes apresentaram resultados significativos para a sua aplicabilidade. Se tratando da média geral do instrumento, Merino e Lívia (2009) sugerem que a média de um instrumento mediante cinco juízes deve apresentar elevados níveis de confiança em relação às questões, como também em relação aos juízes.

Notoriamente, o instrumento atingiu após a segunda rodada de avaliações níveis elevados de média e do coeficiente de $\mathrm{V}$ de Aiken, considerando um instrumento válido (Aiken, 1985). Em suma, esta técnica para validação é utilizada em diversos instrumentos, tanto para questionários, quanto para instrumentos de observação, como também utilizada em diversas áreas do conhecimento, podendo ser considerada uma técnica segura e eficaz para se validar instrumentos de pesquisas (Gamonales et al., 2016).

Em relação aos resultados apresentados na tabela, pode-se mencionar que em cada uma das dimensões (clareza de linguagem, pertinência prática e relevância teórica), os resultados foram satisfatórios em todas as 29 questões após a segunda rodada, em destaque para questões que atingiram o V de Aiken máximo. É importante mencionar que a validação de conteúdo é uma 
avaliação pessoal e opinativa, na qual verifica o que o instrumento se propõe a medir por meio do viés de conteúdo (Pasquali, 1999; Cassepp-Borges, Balbinotti, \& Teodoro, 2010), por isso a escolha dos juízes com expertise no ensino das lutas para o contexto escolar torna-se fundamental para a qualidade do instrumento.

O estudo piloto, que por sua vez também atendeu as expectativas de testagem do instrumento, se faz necessário em um processo de validação, em consonância com o processo de validação dos juízes experts para encontrar possíveis falhas que possam ser ajustadas (Gil, 1989). Para tanto, como não houve falhas o instrumento pode ser finalizado, e estar pronto para a sua aplicação com professores de educação física, em todos os níveis de ensino da educação básica.

Se tratando da similaridade das respostas dos professores, os resultados apresentaram índices satisfatórios após a análise de conteúdo e cálculo por meio do software, mesmo se tratando de respostas abertas e fechadas. A importância de realizar o estudo piloto se configura no feedbeck das respostas obtidas, como também na compreensão dos participantes referentes a cada questão (Gil, 1989), nesse contexto, ter contato com o público alvo do instrumento (professores de educação física escolar) torna-se necessário a fim de trazer pequenas adequações as questões (o que ocorreu no instrumento), mesmo já terem sido examinadas pelos pesquisadores e juízes.

É notório que tendo a validação de conteúdo, juntamente com o estudo piloto tornam-se importantes para a qualidade do instrumento, com isso, apresentando resultados que possam predizer se o instrumento se torna capaz de medir o que se propõe (Pasquali, 1999). Nesse sentido, o QEJL será de suma importante para investigações em torno das lutas no âmbito escolar, contribuindo para tentar suprir a carência de instrumentos do tipo questionário com questões tanto abertas quanto fechadas, ademais possíveis investigações poderão priorizar o ensino do professor, além de apresentar um panorama de como está sendo realizado o ensino das lutas nas aulas de educação física pelo mundo.

\section{Considerações finais}

O QELJ foi elaborado com a finalidade de compreender como está sendo realizado o ensino das lutas na educação física escolar, levando em consideração três dimensões, que mapeiam os conteúdos, as estratégias, os paradigmas e o entendimento dos professores sobre as lutas. Além disso, o interesse foi de contribuir para uma reflexão sobre as lutas no âmbito das aulas de educação física da educação básica.

0 processo de construção do instrumento apresentou indicadores de avaliação para as 29 questões, pautados na literatura sobre jogo e sobre lutas. O QELJ apresentou percentuais satisfatórios na avaliação de conteúdo, realizada por juízes experts, como também no estudo piloto, mediante a isto, o instrumento torna-se válido preliminarmente e pode ser utilizado para compreender o ensino das lutas na educação física escolar.

Este estudo apresenta como limitações, a validação apenas de conteúdo. Nesse sentido, recomenda-se para futuros estudos outras validações psicométricas deste instrumento, como por exemplo: a validação de critério e a validação de constructo, as quais podem auxiliar na finalidade do instrumento. Além disso, recomenda-se a tradução e validação transcultural do instrumento para outros idiomas, oportunizando a sua utilização em diferentes países.

Pode-se concluir que o QELJ pode contribuir de maneira significativa para investigações sobre lutas no âmbito escolar, oportunizando aos professores investigados realizar reflexões sobre suas práticas e aos pesquisadores um panorama de como está sendo realizado o ensino das lutas, mediante as sistematizações e as propostas pedagógicas dos professores investigados. Ademais, sugere-se a criação de outros instrumentos que possam também investigar os alunos, os planejamentos de ensino dos professores e observar suas aulas, oportunizando resultados significantes para o avanço científico e pedagógico do ensino das lutas.

\section{Referências}

Aiken, L. (1985). Three coefficients for analyzing the reliability and validity of ratings. Educational and Psychological Measurement, 45(1), 131-142. doi: $10.1177 / 0013164485451012$ 
Aljadeff-Abergel, E. (2013) Karate Kid: Games and Activities for Introducing Karate to Early Elementary Students. Journal of Physical Education, Recreation \& Dance, 82(4), 33-38. doi: 10.1080/07303084.2011.10598612

Antunes, M.M. (2016). A produção acadêmica em lutas, artes marciais e esportes de combate: reflexões e possíveis encaminhamentos. Revista Brasileira de Prescrição e Fisiologia do Exercício, 11(63), 921-924.

Avelar, B., \& Figueiredo, A. (2009). La iniciación a los deportes de combate: interpretación de la estructura del fenómeno lúdico luctatorio. Revista de Artes Marciales Asiáticas, 4(3), 44-57. doi: $10.18002 /$ rama.v4i3.177

Avelar-Rosa, B. \& López-Ros, V. (2019). What happens during a teaching-learning process of martial arts and combat sports with novice - A case-study focused on the joint activity organization analysis. Revista de Artes Marciales Asiáticas, 1492s), 6-8. doi: 10.18002/rama.v14i2s.6020

Bardin, L. (1977). Análise de conteúdo. Lisboa: Edições 70.

Brasil. (2017). Base Nacional Comum Curricular: Educação é a base. Brasília: Ministério da educação.

Breda, M., Scaglia, A.J., Paes, R.R., \& Galatti L.R. (2010). Pedagogia do esporte aplicada às lutas. São Paulo, SP: Phorte.

Caillois, R. (1990). Os jogos e os homens: a máscara e a vertigem. Lisboa: Cotovia.

Cassepp-Borges, V., Balbinotti, M.A.A., \& Teodoro, M.L.M. (2009). Tradução e validação de Conteúdo: uma proposta para a adaptação de instrumentos. In L. Pasquali (ed.), Instrumentação Psicológica: fundamentos e práticas (pp. 506-520). Porto Alegre: Artmed.

Cirino, C., Pereira, M.P.V.C., \& Scaglia A.J. (2013). Sistematização dos Conteúdos das Lutas para o Ensino Fundamental: uma proposta de ensino pautada nos jogos. Revista Mineira de Educação Física, esp.(9), 221-227.

Correia, W.R. (2015). Educação Física Escolar e Artes Marciais entre o combate e o debate. Revista Brasileira de Educação Física e Esporte, 29(2), 337-344. doi: 10.1590/1807$\underline{55092015000200337}$

Freire, J.B., \& Scaglia, A.J. (2003). Educação como prática corporal. São Paulo: Scipione.

Galatti, L.R., Cirino, C., \& Scaglia, A.J. (2015). Reflexões metodológicas do ensino para o processo de iniciação esportiva das lutas. In J.V. Nascimento, E.R. Souza, V. Ramos, \& J.C. Schmitt (eds.), Educação Física e Esporte: convergindo para novos caminhos (pp. 489-511). Florianópolis: UDESC.

Gamonales, J.M., León, K., Muñoz, J., González, S.E., \& Ibáñez, S.J. (2016). Validación del IOLF5C para la eficacia del lanzamiento en fútbol para ciegos. Revista Internacional de Medicina y Ciencias de la Actividad Física y del Deporte, 18(70), 361-381. doi: 10.15366/rimcafd2018.70.010

Gerhardt, T.E., \& Silveira, D.T. (2009). Métodos de pesquisa. Porto Alegre: Editora da UFRGS.

Gil, A.C. (1989). Métodos e técnicas de pesquisa social. São Paulo: Atlas.

Herminda, P.M.V., \& Araújo, I.E.M. (2006). Elaboração e validação do instrumento de enfermagem. Revista Brasileira de Enfermagem, 59(3), 314- 320. doi: 10.1590/S0034$\underline{71672006000300012}$

Hill, M.M., \& Hill, A. (2000). Investigação por questionário. Lisboa: Sílabo.

Jennings, G. (2017). Martial arts pedagogies and practice: A report on the contributions to coaching knowledge. Revista de Artes Marciales Asiáticas, 12(2), 101-105. doi: $10.18002 /$ rama.v12i2.5152

Kusnierz, C., Cynarski, W.J., \& Gorner, K. (2017). Social reception and understanding of combat sports and martial arts by both school students and adults. Ido Movement for Culture. Journal of Martial Arts Anthropology, 17(1), 30-37. doi: 10.14589/ido.17.1.5

Merino, C., \& Livia, J. (2009). Intervalos de confianza asimétricos para el índice la validez de contenido: Un programa visual basic para la V de Aiken. Anales de Psicología, 25(1), 169-171.

Nascimento, P.R.B., \& Almeida, L. (2007). A tematização das lutas na Educação Física Escolar: restrições e possibilidades, Movimento, 13(3), 91-110. doi: 10.22456/1982-8918.3567

Negrine, A. (2010). Instrumentos de coleta de informações na pesquisa qualitativa. In V. Molina Neto \& A.N.S. Triviños (eds.), A pesquisa qualitativa na Educação Física: alternativas metodológicas (pp. 61-94). Porto Alegre: Universidade/UFRGS/Sulina.

Olivier, J.C. (2000). Das brigas aos jogos com regras: enfrentando a indisciplina na escola. Porto Alegre: Artmed. 
Pasquali, L. (1999). Instrumentos psicológicos: manual prático de elaboração. Brasilia: IBAPP.

Pereira, M.P.V.C., Cirino, C., Correa, A.O., \& Farias, G.O. (2017). Lutas na escola: sistematização do conteúdo por meio da rede dos jogos de lutas. Conexões, 15(3), 338-348. doi: $10.20396 /$ conex.v15i3.8648512

Pereira, M.P.V.C., Farias, G.O., Cirino, C., \& Scaglia, A.J. (2016). 0 jogo como estratégia pedagógica para o ensino da Educação Física escolar no $5^{\underline{0}}$ ano do ensino fundamental I. Corpoconsciência, 20(1), 1-8.

Rufino L.G.B. (2016). Os jogos de lutas nas aulas de educação física escolar: possibilidades técnicotáticas e seus elementos invariantes. Revista Brasileira de Prescrição e Fisiologia do Exercício, 11(63), 917-918.

Rufino, L.G.B., \& Darido, S.C. (2012). Pedagogia do esporte e das lutas: em busca de aproximações. Revista brasileira Educação Física e Esporte, 26(2), 283-300. doi: 10.1590/S1807$\underline{5092012000200011}$

Santa Catarina. (2014). Proposta Curricular de Santa Catarina: formação integral na educação básica. s.l.: Governo do Estado, Secretaria de Estado da Educação.

Theebom, S., \& De Knop, P. (1999). Asian Martial Arts and approaches of instruction in Physical Education. European Journal of Physical Education, 4, 146-161. doi: $\underline{10.1080 / 1740898990040204}$

\section{Anexo: Questionário de Ensino das Lutas e do Jogo (QELJ)}

Este questionário é destinado aos professores de Educação Física da rede Estadual de Educação de Santa Catarina, pertencentes à região da Coordenadoria Regional Grande Florianópolis. Este instrumento está vinculado ao estudo, que tem por analisar o ensino do conteúdo de lutas desenvolvido pelos professores de Educação Física em escolas estaduais da Grande Florianópolis. Para tanto, é muito importante a sua participação. Seguidamente, você está sendo convidado a responder a este questionário de forma sincera e individual. Ademais, os dados obtidos terão tratamento estatístico, para tanto, será mantido o anonimato, por não divulgar o seu nome e demais dados pessoais. Grato por sua contribuição!

\section{Dados de identificação}

1. Nome:

2. Sexo

$$
\text { ( ) Masculino ( ) Feminino }
$$

3. Idade:

4. Assinale a sua formação acadêmica

( ) Graduação ( ) Especialização ( ) Mestrado ( ) Doutorado

5. Tempo de docência:

6. Escola em que atua:

7. Tempo de atuação nesta escola:

\section{Conteúdos desenvolvidos}

A questão 8 é referente aos conteúdos trabalhados nos níveis de ensino, para tanto, responda somente em quais níveis de ensino que você atua no momento.

8. Assinale quais conteúdos utiliza nos níveis de ensino que você atua.

Ensino fundamental I

( ) Brincadeiras e Jogos ( ) Esportes ( ) Ginásticas

( ) Danças ( ) Lutas ( ) Práticas Corporais de aventura ( ) Outros. Quais?

Ensino fundamental II

( ) Brincadeiras e Jogos ( ) Esportes ( ) Ginásticas

( ) Danças ( ) Lutas ( ) Práticas Corporais de aventura ( ) Outros. Quais?

Ensino médio

( ) Brincadeiras e Jogos ( ) Esportes ( ) Ginásticas ( ) Danças

( ) Lutas ( ) Práticas Corporais de aventura ( ) Outros. Quais?

Educação de Jovens e Adultos

( ) Brincadeiras e Jogos ( ) Esportes ( ) Ginásticas ( )

Danças ( ) Lutas ( ) Práticas Corporais de aventura ( ) Outros. Quais? 
A questão 9 é referente aos seus conhecimentos teóricos e práticos a respeito dos conteúdos da Educação Física.

9. Assinale quais os conteúdos você possui maiores conhecimentos teóricos e práticos.

( ) Brincadeiras e Jogos ( ) Esportes ( ) Ginásticas ( ) Danças

( ) Lutas ( ) Práticas Corporais de aventura ( ) Outros. Quais?

As questões 10, 11, 12 e 13 são referentes ao jogo.

10. Você considera o jogo um conteúdo da Educação Física? ( ) Sim ( ) Não

11. Descreva os conhecimentos teóricos e práticos que você possui referente ao jogo.

12. Na graduação, cursou alguma disciplina referente ao jogo? ( ) Sim ( ) Não

Em caso afirmativo, qual(is)?

13. Fez algum curso ou especialização sobre jogo? ( ) Sim ( ) Não

Em caso afirmativo, qual(is)?

As questões 14,15,16,17, 18, 19, 20, 21, e 22 são referentes às lutas.

14. Você considera as lutas um conteúdo da Educação Física? ( ) Sim ( ) Não

Justifique a sua resposta:

15. Em suas aulas, você ensina o conteúdo de lutas? ( ) Sim ( ) Não

Justifique a sua resposta:

16. Você tem algum receio de trabalhar o conteúdo de lutas nas aulas de Educação Física? ( ) Sim ( ) Não

Em caso afirmativo, qual(is)?

17. Você se julga com competência pedagógica para aplicar o conteúdo de lutas? ( ) Sim ( ) Não

Em caso afirmativo, por quê?

Em caso negativo, por quê?

18. Você já praticou alguma modalidade de luta? ( ) Sim ( ) Não

Em caso afirmativo, qual(is)? E por quanto tempo?

19. Caso tenha praticado, qual a sua graduação (faixa, mestre, iniciante) na modalidade de luta?

20. Como você compreende o conceito de lutas? Quais práticas de luta você conhece?

21. Na graduação, cursou alguma disciplina de lutas? ( ) Sim ( ) Não

Em caso afirmativo, qual(is)?

22. Fez algum curso ou especialização de lutas? ( ) Sim ( ) Não

Em caso afirmativo, qual(is)?

\section{Propostas e estratégias pedagógicas}

As questões 23, 24, 25, 26, 27, 28, e 29 são referentes aos métodos e estratégias de ensino, como também os benefícios dos conteúdos e a sistematização e organização dos mesmos.

23. Descreva quais estratégias utiliza para ensinar os conteúdos desenvolvidos em suas aulas.

24. Considera o jogo uma estratégia de ensino para os conteúdos? Justifique a sua resposta.

25. Exemplifique um conteúdo que pode ser ensinado por meio do jogo. Justifique a sua resposta.

26. As lutas podem ser ensinadas por meio do jogo? ( ) Sim ( ) Não Justifique a sua resposta.

27. Assinale quais habilidades motoras podem ser desenvolvidas e/ou refinadas por meio do conteúdo das lutas.
( ) Agarrar
( ) Reter
( ) Esquivar
( ) Resistir
( ) Desequilibrar
( ) Imobilizar
() Cair
( ) Manipular objetos
( ) Livrar
( ) Rolar
( ) Girar
( ) Tocar
( ) Puxar
( ) Saltar
( ) Derrubar
( ) Correr
( ) Empurrar
( ) Andar
( ) Lançar
( ) Outras Quais?

28. Existem benefícios em ensinar lutas na escola? ( ) Sim ( ) Não Justifique a sua resposta.

29. Se você trabalha o conteúdo de lutas em suas aulas, como você sistematiza (organiza) este conteúdo? 


\section{Author's biographical data}

Marcos Paulo Vaz de Campos Pereira (Brazil). Doutorando do Programa de Pós-Graduação em Ciências do Movimento Humano, Universidade do Estado de Santa Catarina. Mestre em Ciências do Movimento Humano. Membro do Laboratório de Pesquisa em Práticas Pedagógicas da Educação Física (LAPRAPEF). Pesquisador nos seguintes temas: jogo, pedagogia do esporte, educação física escolar e lutas. E-mail: marcosp.pereira46@gmail.com

Íris Dantas da Mota (Brazil). Doutorando do Programa de Pós-Graduação em Ciências do Movimento Humano, Universidade do Estado de Santa Catarina. Mestre em Ciências do Movimento Humano. Membro do Laboratório de Pesquisa em Práticas Pedagógicas da Educação Física (LAPRAPEF). Pesquisadora nos seguintes temas: atividade física e saúde, educação física escolar e síndrome de Burnout. E-mail: irisdantas83@gmail.com

Elias Barboza Lacerda (Brazil). Mestre em Ciências do Movimento Humano. Membro do Laboratório de Pesquisa em Práticas Pedagógicas da Educação Física (LAPRAPEF), Universidade do Estado de Santa Catarina. Pesquisador nos seguintes temas: atividade física e saúde, educação física escolar e educação física adaptada. E-mail: eliasblacerda@hotmail.com

Gelcemar Oliveira Farias (Brazil). Professora Adjunta da Universidade do Estado de Santa Catarina (Brasil). Coordenadora do Laboratório de Pesquisa em Práticas Pedagógicas da Educação Física (LAPRAPEF). Pesquisadora nos seguintes temas: Formação e desenvolvimento profissional de professores e educação física escolar. E-mail: fariasgel@hotmail.com 